\title{
Preparation of Possible P Selectin Inhibitor from Bovine Thyroglobulin, (Di-hydrido) Sulfo Hydrate 1, 5 Anhydro L-fucitol
}

\author{
Jesus Christus, Michael Arden Madson \\ Research and Development BioLogistics LLC Ames, Iowa, USA
}

Email address:

mmadson53@earthlink.net (M. A. Madson)

\section{To cite this article:}

Jesus Christus, Michael Arden Madson. Preparation of Possible P Selectin Inhibitor from Bovine Thyroglobulin, (Di-hydrido) Sulfo Hydrate 1, 5 Anhydro L-fucitol. World Journal of Food Science and Technology. Vol. 5, No. 1, 2021, pp. 6-9. doi: 10.11648/j.wjfst.20210501.12

Received: May 10, 2019; Accepted: June 10, 2019; Published: January 12, 2021

\begin{abstract}
P selectin is known to mediate several disease states through the binding of epitopes on the surface of endothelial cells. These diseases include cancer, cancer metastasis and inflammation. Sulfo Lewis a is a sulfated oligosaccharide could bind P selectin. A possible novel inhibitor of P-selectin binding may attenuate these diseases. One possible inhibitor is prepared from bovine thyroglobulin in one step, with appropriate work-up, from a readily abundant source, bovine thyroid gland, via novel chemistry. That molecule is (di-hydrido) sulfo hydrate 1,5 anhydro L-fucitol. This chemistry is known to occur for the preparation of 1, 5 anhydro oligosaccharides from $\mathrm{K}$ casein and bovine milk. Another example of this chemistry has also been prepared; the di-(hydrido) di-phosphate di-hydrate 2, 5 anhydro mannitol (glucitol) from an ethanol extract of banana fruit. The molecule, here, would be the first report of $\mathrm{H}^{-}$nucleophile attack of a non-phosphorylated glycoside. In addition to components of the O-linked oligosaccharide, to originate from bovine thyroglobulin requiring a tyrosine sulfate for binding. This work provides methods for preparing (di-hydrido) sulfo 1, 5 anhydro L-fucitol, as a possible inhibitor of P-selectin binding, in addition to those reported. These include; the di (di-hydrido) trisaccharide di-(hydrido) di-phosphate di-hydrate serinyl (dihydrido) sulfo tyrosine dipeptide as well as the tri (di-hydrido) sulfo tri-hydrate 1,5 anhydro trisaccharide alditol. Both of the latter two originate from bovine thyroglobulin and have been or will, possibly, be reported.
\end{abstract}

Keywords: P-selectin Inhibitor, $\mathrm{H}^{-}$Nucleophilic Attack, Bovine Thyroglobulin-Source, Mass Spectrometry

\section{Introduction}

P selectin is involved in several disease states, thrombosis, cancer, cancer metastasis and inflammation [1], Sulfo lewis a is known to bind $\mathrm{P}$ selectin [2]. And these authors have synthesized sulfated neoglycopolymers as selective inhibitors, mimics for binding epitopes to study this binding [2]. The molecular components found to be derived from the O-linked oligosaccharide from bovine thyroglobulin, after treatment with $\mathrm{NaBH}_{4}$ in $\mathrm{NH}_{4} \mathrm{OH}$ is thought to be contain L-fucose, D$\mathrm{N}$-acetyl glucosamine and glucose substituted with derivatized sulfate linked to derivatized di-phospho serinyl derivatized sulfo tyrosine dipeptide and the corresponding 1, 5 anhydro alditol trisaccharide tri-(di-hydrido) sulfate [3-4]. Although the report depicts the anomeric linkages and linkage position, only the 'reducing sugar' of the substituted trisacchride is known. It is shown to be glucose. This monosaccharides are similar in structure to sulfo lewis a and because of the simplicity of the chemistry and work-up, the source is readily available the testing of these molecules for P-selectin inhibitors, would be reasonable. In this report the (di-hydrido) sulfo hydrate of L-fucitol is prepared in order to aid in the determination of $\mathrm{P}$ selectin binding requirements and because of the simplicity of its preparation and isolation this derivatized sulfo analogue of L-fucitol, is given. The chemistry to prepare L-fucitol 1, 5 anhydro molecule, is known to occur with preparation of di-(hydrido) di-phospho di-hydrate 2, 5 anhydro mannitol (glucitol) and this chemistry is applied in this report [5]. A simple method for testing the inhibition of binding of the sulfo lewis a epitope by these three molecules can be done with the use of recently reported carbohydrate affinity columns. [6] 


\section{Materials and Methods}

Bovine thyroglobulin $(<0.30 \mathrm{mg}$, Sigma-Aldrich Chemical Co., Saint Louis MO, USA) was placed in a reaction vial. To this vial is added $\mathrm{NH}_{4} \mathrm{OH}(1 \mathrm{~N}, \mathrm{pH} 11.4,1.00$ $\mathrm{mL})$ and $\mathrm{NaBH}_{4}\left(3 \mu \mathrm{L}\right.$ of a $4 \mathrm{~N}$ solution) is added at $\mathrm{t}_{0}$. The vial is allowed to stand at ambient temperature for 24 hours, un-capped. The solution is pushed through an $\mathrm{NH}_{4}{ }^{+}$form cation exchange cartridge $\left(1.0 \mathrm{~mL}\right.$, prepared from a $\mathrm{H}^{+}$form cation exchange cartridge by pushing $\mathrm{NH}_{4} \mathrm{OH}(1 \mathrm{~N}, \mathrm{pH} 11.4)$ and washed with 10 volumes of $\mathrm{H}_{2} \mathrm{O}$ (18 mega Ohm resistivity, Millipore Co., New England, USA). The effluent from the $\mathrm{NH}_{4}{ }^{+}$cation exchange cartridge is evaporated with a stream of $\mathrm{N}_{2}$ to no less than $200 \mu \mathrm{L}$ in volume. To this solution is added $\mathrm{H}_{2} \mathrm{O}(1.00 \mathrm{~mL}, 18$ mega $\mathrm{Ohm}$ resistivity, Millipore Co., New England, USA). The effluent is then passed through a $\mathrm{Na}^{+}$form cation exchange cartridge and the effluent frozen prior to analysis by $\mathrm{ms}$ and $\mathrm{ms}^{2}$ with an API 2000 triple quadrapole mass spectrometer (ABSciex, Sunnyvale CA, USA).

\section{Results and Discussion}

Sulfated and phosphorylated esters of carbohydrate are known to be isobaric in the mass spectrometer, underivatized. However treatment of sulfated or phosphorylated with $\mathrm{NaBH}_{4}$ in $\mathrm{NH}_{4} \mathrm{OH}$ is known to produce the (di-hydrido) and the (hydrido) derivatives for sulfated and phosphorylated carbohydrate esters, respectively. [7] Also, another anion, carbonate, is known to yield hydride substitution products, that is, from bicarbonate, and sparged air, with $\mathrm{NaBH}_{4}$ in $\mathrm{NH}_{4} \mathrm{OH}$. [8]

The reaction products from the treatment of bovine thyroglobulin with $\mathrm{NaBH}_{4}$ in $\mathrm{NH}_{4} \mathrm{OH}$ generate a mass spectrum with two products having three ions. These ions are $\mathrm{m} / \mathrm{z} 97.0, \mathrm{~m} / \mathrm{z} 265.3$ and $\mathrm{m} / \mathrm{z} 673.4$. The mass spectrum is shown in Figure 1.

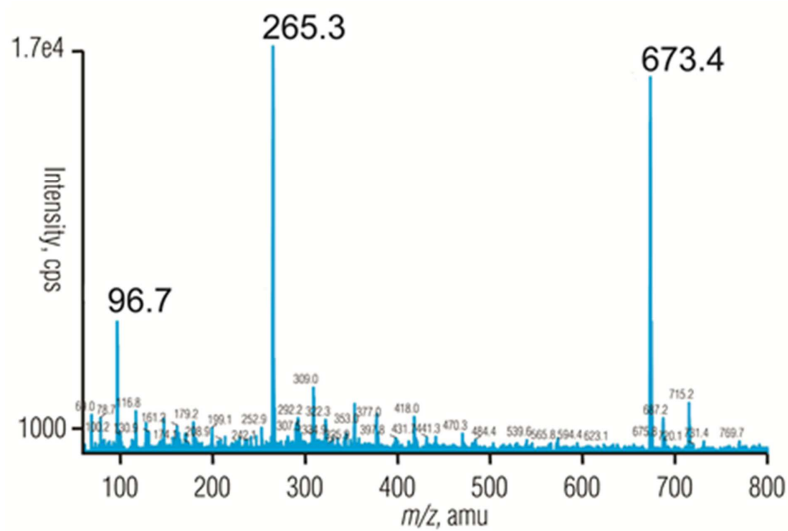

Figure 1. API mass spectrum from products formed from treatment of bovine thyroglobulin with $\mathrm{NaBH}_{4}$ in $\mathrm{NH}_{4} \mathrm{OH}$.

The products' structures are shown in Figures 2 and 3. Recovery of the whole molecule is shown in Figure 2, a doubly charged ion.

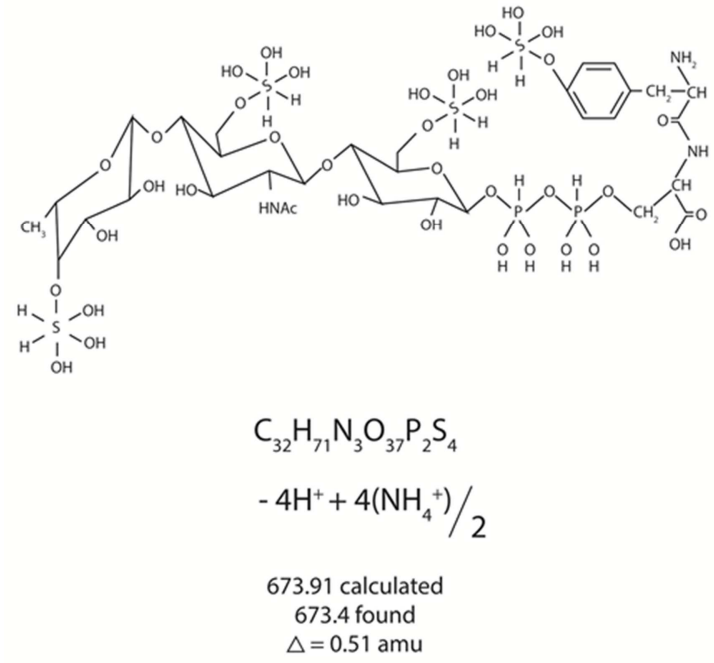

Figure 2. Oligosaccharide-linked to di-(hydrido) di-phospho serinyl (dihydrido) sulfo tyrosine from bovine thyroglobulin after treatment with $\mathrm{NaBH}_{4}$ in $\mathrm{NH}_{4} \mathrm{OH}$.

The 1, 5 anhydro oligosaccharide is not present because the reaction vessel is un-capped. The $\mathrm{pH}$ drop is possibly due to the evolution of $\mathrm{NH}_{3}(\mathrm{~g})$ during the reaction. This drop in $\mathrm{pH}$ prevents the ionization of the hydrated di-(hydrido) diphospho group at the anomeric center of the 'reducing' monosaccharide component of the total molecule cleaved out from bovine thyroglobulin. When ionized the phospho hydrate collapses to a $\mathrm{P}=\mathrm{O}$ bond, releasing $\mathrm{H}_{2} \mathrm{O}$ by accepting an $\mathrm{H}^{+}$ion from $\mathrm{NH}_{4}{ }^{+}$and evolving $\mathrm{NH}_{3}(\mathrm{~g})$ to the atmosphere. The hydrido-phosphoryl group would be anti-periplanar to a non-bonding $\mathrm{O}$ atom. This weakens the $\mathrm{C}-1$ atom to $\mathrm{O}-1$ atom bond and allows nucleophilic attack by hydride at the anomeric center to produce the 1,5 anhydro oligosaccharide alditol. This has been found to be the case for molecules, Kappa casein and bovine milk $[9,10]$.

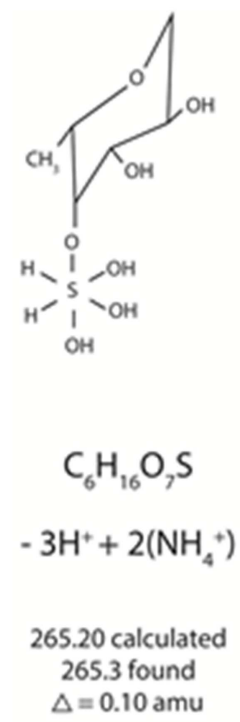

Figure 3. (di-hydrido) sulfo hydrate 1, 5-anhydro L-fucitol anion from bovine thyroglobulin treated with $\mathrm{NaBH}_{4}$ in $\mathrm{NH}_{4} \mathrm{OH}$. 
A report of $\mathrm{H}^{-}$attack of a hemi-ketal has been accepted for publication [5]. The 2, 5 anhydro di (hydrido) di-phospho dihydrate mannitol (glucitol) has been prepared by treatment of neokestose 1, 6 diphosphate, found in banana fruit ethanol extract, with $\mathrm{NaBH}_{4}$ in $\mathrm{NH}_{4} \mathrm{OH}$.

The (hydrido) hydrate sulfo 1, 5 anhydro-L-fucitol, $\mathrm{m} / \mathrm{z}$ 265.3, is depicted in Figure 3.

The glycoside may have its O-1" "atom aligned such that one of its non-bonding orbitals is not anti-periplanar to an incoming nucleophile, $\mathrm{H}^{-}$. However, the $\alpha$ face provides an anti-bonding orbital for an approaching nucleophile from the O-1" "to C-1" "sigma bond, in a possible $\mathrm{SN}_{2}$ fashion, giving the 1, 5-anhydro (di-hydrido) sulfo-L-fucitol, see Figure 4.

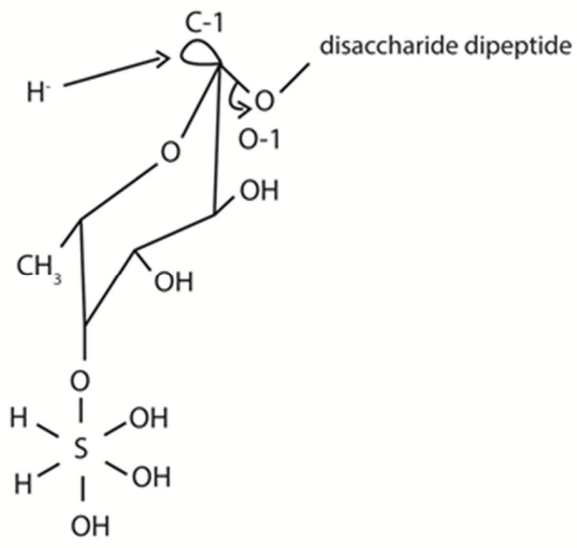

Figure 4. Possible mechanism for the formation of (di-hydrido) sulfo hydrate 1, 5-anhydro L-fucitol from bovine thyroglobulin after treatment with $\mathrm{NaBH}_{4}$ in $\mathrm{NH}_{4} \mathrm{OH}$.

The $\mathrm{ms}^{2}$ for $\mathrm{m} / \mathrm{z} 265.3$ is not shown. However it yields two ions only; $\mathrm{m} / \mathrm{z} 79.8$ and $\mathrm{m} / \mathrm{z}$ 97.2. The firs ion, $\mathrm{m} / \mathrm{z} 79.8$, is diagnostic for sulfated molecules, a zwitterionic $\mathrm{SO}_{3}{ }^{-}$. There is no diagnostic ion for phosphate at $\mathrm{m} / \mathrm{z} 79.0$. The second ion, $\mathrm{m} / \mathrm{z}$ 97.2, can be either $\mathrm{HSO}_{4}^{-}$or $\mathrm{H}_{2} \mathrm{PO}_{4}^{-}$. However, $\mathrm{H}_{2} \mathrm{PO}_{4}{ }^{-}$is not present, as noted above.

The ion, $\mathrm{m} / \mathrm{z} 265.3$, could have another identity. In addition to the anhydro alditol, noted, the (di-hydrido) sulfo tyrosine is possible. This tyrosine sulfate analogue is likely to remain on the cation exchange resin because the amino acid derivative would be a cation bound to the cation exchange cartridge. Therefore, the (di-hydrido) di-phospho hydrated sulfo 1, 5 anhydro L-fucitol is present only.

With other derivatives of bovine thyroglobulin oligosaccharide dipeptide and its 1, 5 anhydro oligosaccharide analogue, [3], potential inhibitors of $\mathrm{P}$ selectin could be discovered.

\section{Conclusions}

This discloses novel chemistry, $\mathrm{H}^{-}$nucleophilic attack of the fucosylated bovine thyroglobulin oligosaccharide dipeptide. The resulting molecule could be used as a possible P-selectin inhibitor. It may be used (tested) as an inexpensive molecule for the treatment of cancer metastasis and inflammation. It would add to the structural characterization of possible molecules binding P-selectin. Under another title, which is currently under review, is, detailing their preparation and characterization, a bovine thyroglobulin oligosaccharide dipeptide and its 1,5 anhydro oligosaccharide. These could be used to help characterize P-selectin binding to oligosaccharides and their derivatives, especially the contribution of L-fucose to P-selectin binding with use of Lfucosyl affinity chromatography. [6, 11-14]

Workers have proposed a mechanism for the nucleophilic attack of furanosyl acetals. This mechanism may apply to the nucleophilic attack of neokestose 1, 6 di-phosphate. That is Attack by $\mathrm{H}^{-}$to produce 2, 5 anhydro 1, 6 di-(hydrido) diphospho di-hydrate mannitol (glucitol) prepared in a manner similar to the title compound. This mechanism may also apply to the furansoyl glycoside found in bovine thyroglobulin O-linked oligosaccharide dipeptide. [15]

With the synthesis and isolation of 1, 5 anhydro (dihydrido) hydrate sulfo L-fucitol, it may be an inhibitor of $\mathrm{P}$ selectin activity and may be a treatment for cancer metastasis and inflammation. Because this molecule is simply prepared, it can be harvested from cattle thyroid glands, at slaughter, the use of this molecule could add value to cattle.

\section{References}

[1] Geng, J-G; Chen, M.; Chou, Kuo-C. P-selectin Cell Adhesion Molecule in Inflammation, Thrombosis, Cancer Growth and Metastasis Current Medicinal Chemistry 11 (16) 2153-2160 (8) (2004).

[2] Manning, D.; Hu, X.; Beck, P.; Kiessling, L.; Synthesis of Sulfated Neoglycopolymers: Selective P-Selectin Inhibitors Journal of the American Chemical Society 119 (13), 31613162 DOI: $10.1021 /$ ja964046x (1997).

[3] Christus, J.' Madson, M.; Possible treatment for malaria to mimic and inhibit Duffy Binding Protein II (DBP II) monomer 2 binding to DBP II monomer 1; sulfo tyrosine oligosaccharide dipeptide from bovine thyroglobulin World Journal of Food Science and Technology, manuscript under review (2019).

[4] Leppänen, A.; White, S.; Helin, J.; McEver, R.; Cummings, R.; Binding of Glycosulfopeptides to P-selectin Requires Stereospecific Contributions of Individual Tyrosine Sulfate and Sugar Residues J. Biol. Chem. 275 39569-39578 (2000).

[5] Christus, J.; Madson, M.; Preparation of 2, 5-anhydro di(hydrido) di-phosphate di-hydrate Mannitol (Glucitol) from Banana Fruit Yields a Possible Fructose 1, 6 Bisphosphate Aldolase Inhibitor (s), accepted for publication, World Journal of Food Science and Technology (2019).

[6] Madson, M.; Affinity/lectin chromatography methods, patent, US 9, 522, 382 B2 (2016).

[7] Madson, M.; Method of discerning substitution of carbohydrate esters, patent, US 9, 726, 671 B2 (2017).

[8] Madson, M.; Manufacturing of $\mathrm{MEOH}$, formaldehyde, formic acid and ammonium penta-borate tetra-hydrate from $\mathrm{CO}_{2}$, patent, US 8, 685, 355 B2 (2014). 
[9] Christus, J.; Madson, M.; Possible Mimics of Duffy Binding Protein-II for Plasmodium vivax Binding Endothelial Cells or Binding Plasmodium falciparum by Mimicking Epitope on Erythrocyte Binding Antigen-175 A World Journal of Food Science and Technology 2 (2) 44-54 (2018).

[10] Christus, J.; Madson, M.; Possible Treatment of Mycobacterium lepramatous with Bovine Milk World Journal of Food Science and Technology 2 (3) 55-61 (2018).

[11] Norgard, K.; Moore, K.; Diaz, S.; Stults, N.; Ushiyama, S.; McEver, R.; Cummings, R.; Varki, A.; Characterization of a specific ligand for P-selectin on myeloid cells. A minor glycoprotein with sialylated O-linked oligosaccharides. J. of Biol. Chem. 268 12764-12774. (1993).

[12] Nelson, R.; Cecconi, O.; Roberts, W.; Aruffo, A.; Linhardt, R.; Bevilacqua, M.; Heparin oligosaccharides bind L- and Pselectin and inhibit acute inflammation Blood 82: 3253-3258; (1993).
[13] Malý, P.; Thall, A.; Petryniak, B.; Rogers, C.; Smith, P.; Marks, R.; Kelly, R.; 1 Gersten, K.; Cheng, G.; Saunders, T.; Camper, S.; Camphausen, R.,.; Sullivan, F.; YukihiroIsogai;, Hindsgaul, O.; Andrian, U.; Lowe, J.; The $\alpha(1,3)$ Fucosyl transferase Fuc-TVII controls leukocyte trafficking through an essential role in L-, E-, and P-selectin ligand biosynthesis Cell 86 (4) 23 643-653 (1996).

[14] Ohmori, K.; Kanda, L.; Mitsuoka, C.; Kanamori, A.; KurataMiura, K.; Sasaki, K.; Nishi, T.; Tamatani, T.; Kannagi, R.; Pand E-Selectins recognize sialyl 6-sulfo lewis $\mathrm{x}$, the recently Identified L-Selectin ligand Biochem. Biophys. Res. Commun. 278 (1) 90-96 (2000).

[15] Larsen, C.; Ridgway, B.; Shaw, J.; Woerpel, K.]; A Stereoelectronic Model To Explain the Highly Stereoselective Reactions of Nucleophiles with Five-Membered-Ring Oxocarbenium Ions Department of Chemistry, University of California Irvine, California 92697-2025 J. Am. Chem. Soc. 12 (151) 12208-12209 (1999). 